\title{
Quando o Educador do Ano é um educomunicador: - papel da USP na legitimação do conceito
}

Ismar de Oliveira Soares

Pós-doutor pela Marquette University, Milwaukee, USA. Professor da Escola de Comunicações e Artes da Universidade de São Paulo. Presidente da UCIP - Union Catholic Internationale de la Presse (Genebra, Suiça). Membro do Pontifício Conselho para as Comunicações Sociais do Vaticano. Jornalista responsável pela revista Comunicação \& Educação. Membro do Conselho Editorial da revista Comunicar, Universidad de Huelva, Espanha. Coordenador do Núcleo de Comunicação e Educação da USP - <http://www.usp.br/nce>.

E-mail: ismarolive@yahoo.com

Resumo: O ano de 2007 foi especialmente marcante para o grupo das 10 escolas com as maiores notas na Prova Brasil. Chegaram lá porque todas, independentemente da qualidade de suas infra-estruturas ou do grau socioeconômico de seus alunos, adotam permanentemente práticas educomunicativas que envolvem a arte e a produção midiática. Foi um ano especial também para esta revista e para a ECA/USP, uma vez que um de seus docentes, Ismar de Oliveira Soares, após consulta na internet pelo Grupo Educartis, foi indicado para receber o título de Educador do Ano ${ }^{1}$, por seu envolvimento com a Educomunicação. Neste artigo, num texto de caráter autobiográfico, a pedido da revista Comunicação \& Educação, Ismar de Oliveira Soares apresenta aos leitores a formulação e a consolidação do conceito a partir do qual um número considerável de educomunicadores se transformam, no coração de seus alunos, em "educadores do ano", em suas escolas, ONGs e comunidades.

Palavras-chave: educação, comunicação, educomunicação, escola, recepção.
Abstract: 2007 was a specially outstanding year for the 10 schools group with the highest grades in "Prova Brasil". They reached that position because, independent of their infrastructure quality or of their students socioeconomic level, all of them adopt permanently educommunicative practices that involve art and mediatic production. It was also a special year for this journal and for ECA/USP because one of its professors, Ismar de Oliveira Soares, after an Internet survey by Grupo Educartis, was indicated to receive the title of Educator of the Year, for his involvement with Educommunication. In this article, in a text of autobiographic characteristic written by request of Revista Comunicação \& Educação, Ismar de Oliveira Soares introduces to readers the formulation and consolidation of the concept by which a remarkable number of educommunicators become, in their students' heart, "educators of the year", in their schools, NGOs and communities.

Keywords: education, communication, educommunication, school, reception.
Recebido: 14.6 .2008

Aprovado: 17.6 .2008

1. O Educare - Prêmio Nacional de Excelência na Educação é uma realização da EDUCARTIS. Trata-se de um Prêmio que reúne casos dos mais diversos setores ligados à educação pública, privada e corporativa, em todos os níveis. A categoria "Educador do Ano" é concedida a uma personalidade com atuação ímpar em favor da educação nacional. O Prêmio Educador do Ano/2007 foi outorgado ao Prof. Dr. Ismar de Oliveira Soares, no dia 12 de dezembro de 2007, no auditório do SESC-Vila Mariana, em São Paulo. Disponível em: <http://www.premioeducare.com.br/vencedores2007.asp>. 
comunicação \& educação • Ano XIII • Número 3 • set/dez 2008

Ouve-se com freqüência, nos meios acadêmicos, em espaços onde se definem políticas públicas e, especialmente, no campo da prática profissional, que a Educomunicação já se apresenta como uma alternativa real de trabalho e de ação educativa. O fato levou a Escola de Comunicações e Artes da Universidade de São Paulo - ECA/USP, avessa a novidades e ciosa de sua liderança nacional no campo da formação de comunicadores, a deliberar pela criação de uma licenciatura voltada especificamente ao novo campo.

Há 20 anos, a ECA vinha se preparando para este momento. De 1989 a esta data, um grupo de professores, pesquisadores e agentes culturais vinculados à Escola trabalhou arduamente na identificação e na construção de um referencial teórico-metodológico para o tratamento dos temas que emergem na interface Comunicação/Educação.

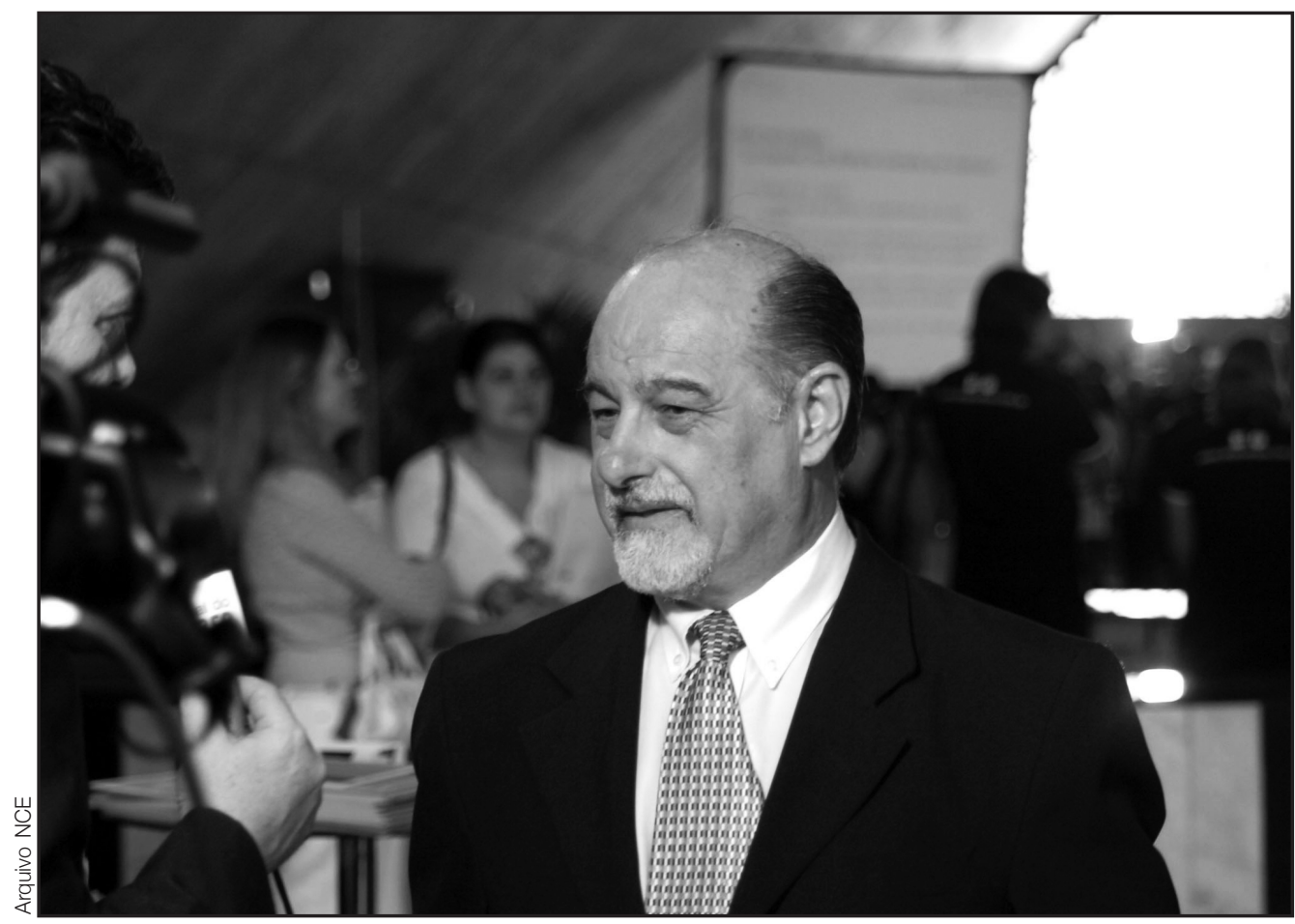

O Prêmio Educador do Ano/2007 foi outorgado ao Prof. Dr. Ismar de Oliveira Soares.

Ao sermos instados a produzir um breve memorial sobre o caminho percorrido em torno do tema por nós mesmos e por um seleto grupo de docentes e de alunos da USP, lembramos, inicialmente, que o conceito sobre o qual nos debruçamos vem sendo descoberto e reconhecido, há mais tempo, pela juventude, pela paixão que desperta. Namorar o Educom foi justamente o lema do V Encontro dos Jovens Educomunicadores, promovido pela Fundação Hélio Augusto de Souza, em São José dos Campos, em 12 de junho de 2008. Ao converter-se em objeto de desejo, para uns, apresenta-se como estranho e inadequado para outros. Algo, enfim, que merece uma análise mais acurada que a Revista decidiu fazer neste artigo. 


\section{O RECONHECIMENTO INTERNACIONAL}

No dia 22 de maio de 2008, por ocasião da abertura do Congresso Internacional de Faculdades de Comunicação das Universidades Católicas, convocado pelo Pontifício Conselho para as Comunicações Sociais (PCCS), o Prof. Pier Cesare Rivoltella, da Católica de Milão, tomou a iniciativa de referir-se publicamente, em sua palestra, à Educomunicação.

Para o professor de Milão, o conceito sistematizado pelo Núcleo de Comunicação e Educação da USP, no Brasil, deveria ser entendido como uma prática de mediação cultural, cabendo ao educomunicador transformar-se num profissional em condições de ser uma presença significativa na vida das novas gerações. A referência a este novo tipo de trabalhador da cultura foi ilustrada, pelo conferencista, como uma exigência dos novos tempos, quando uma pesquisa com oito mil adolescentes europeus de 12 a 18 anos dera conta de que os jovens que avançaram, em passado recente, na promoção de práticas horizontais de comunicação, facilitadas pelos novos recursos tecnológicos (diálogo entre pares e uma considerável e crescente distância em relação ao mundo dos adultos), mostravam-se interessados, no momento, em buscar um diálogo mais profundo com adultos capazes de socializar experiências para lhes facilitar a formulação de sentidos de vida. A figura deste adulto, segundo Rivoltella, corresponderia ao perfil descrito pelo ideário da Educomunicação: um profissional que conhece profundamente os campos da comunicação e da educação, maneja as tecnologias da informação e mantém-se aberto a um constante diálogo intercultural com as novas gerações, associando-se a elas na promoção de espaços de produção de cultura.

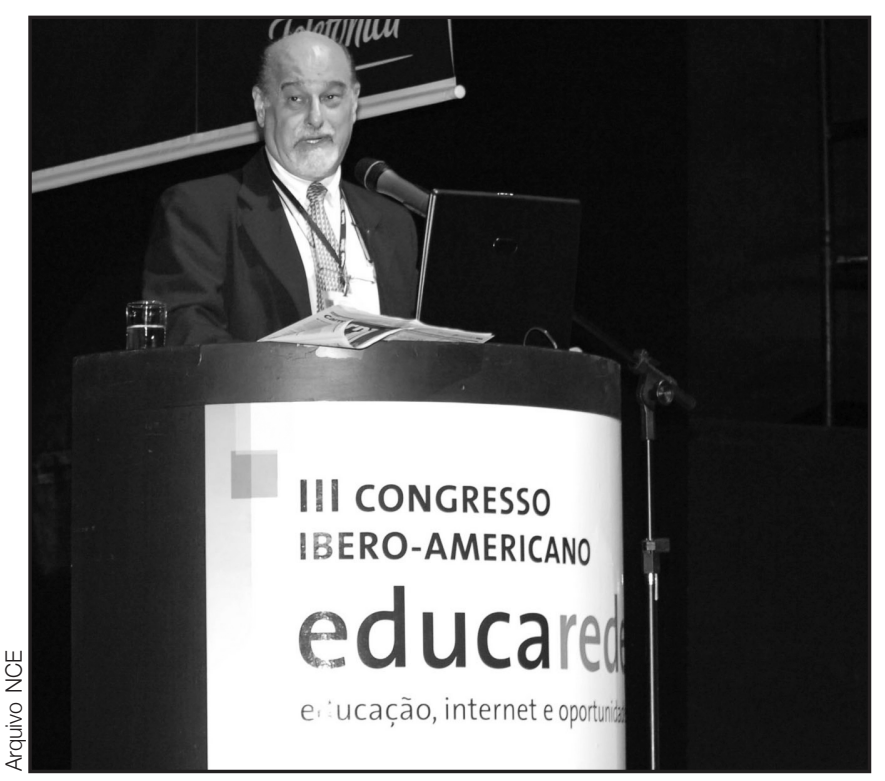

Democratizar a educação foi a mensagem que o Prof. Dr. Ismar levou ao III Congresso Ibero-americano Educarede, que reuniu mais de 1,5 mil professores, assessores técnicos, coordenadores e outros profissionais da Educação no Memorial da América Latina, em São Paulo (SP), nos dias 29 e 30 de maio de 2006.
A identificação do conceito e a referência a ele num contexto determinado, no evento de Roma, não fora a primeira manifestação de apreço, no exterior, ao tema em pauta. Em 2000, em Caracas, Venezuela, um grupo de 50 dirigentes que constituíam a Equipe de Comunicação Social (ECOSAM), da Congregação das Irmãs Salesianas, após promover um workshop de uma semana, em que se confrontaram a reflexão e a prática dos educadores de suas instituições nas três Américas 
2. "Asi Comprendemos la Educomunicación", transcrito do site da Equipe de Comunicação Social das Filhas de Maria Auxiliadora nas Américas. Disponível em: <http:// www.ecosam.org/index. php?option $=$ com_conte $n$ t\&task= view\&id $=21$ \& temid $=1$. Aceso em 15 jun. 2008>.

3. Lembramos Nely de Camargo, consultora internacional e que colaborou para a criação do NCE/USP; Osvaldo Sangiorgi, fundador do Núcleo de Cibernética Pedagógica; Luiz Barco, com seus artigos para a revista Super Interessante e sua atuação como professor de matemática nos telecursos da TV Cultura; Elza Dias Pacheco, com suas pesquisas sobre in fância e mídia, a partir da vertente da psicologia social; Maria Immacolata Vassalo de Lopes e Mauro Wilton, com suas pesquisas sobre o fenômeno da recepção; Dilma de Melo Silva e Solange Couceiro de Lima, com seus trabalhos de orientação no campo da antropologia da comunicação; Maria Aparecida Baccega e Adilson Odair Citelli, com seus trabalhos sobre linguagem e comunicação; Luiz Roberto Alves, na área da comunicação e cultura Maria Cristina Castilho Costa, envolvida com os temas da estética e das tecnologias da informação na educação: Maria Stella Orcini e Elza Dias Adjemberg, com suas incursões na área da arte/educação. O grupo foi enriquecido, ainda, ao longo da recente história do CCA, com a presença de pesquisadoras como Maria Lourdes Motter (recepção de telenovelas), Roseli Fígaro (comunicação e trabalho) e Lucilene Cury (tecnologias da comunicação).

4. Coordenação do Projeto TAT - Treinamento de Análise da Televisão, com os resultados da pesquisa do Núcleo de Comunicação e Educação - NCE/ USP, concluída um ano antes, decidiu adotar a prática da Educomunicação, em nível continental, tornando-a válida - como meta a ser alcançada progressivamente - para mais de 1.200 obras nas três Américas. Sobre a opção das irmãs salesianas, afirmou-se:

ECOSAM llega a la educomunicación después de varios años de estudio y de búsquedas en los que va diseñando un mapa de comprensiones en diálogo con las Facultades de Comunicación Social a través de la participación sistemática a los encuentros de FELAFAC (Federación Latinoamericana de Facultades de Comunicación Social) y de los estudios realizados por las hermanas. Se opta por la valiosa asesoría de Ismar de Oliveira Soares, cuando se quería plasmar en una propuesta, los enfoques comunicativos adquiridos hasta el momento, tales como: el desplazamiento de los medios a las mediaciones, y los binomios comunicación - cultura, comunicación - ciudadanía, comunicación solidaridad, comunicación - educación. La Propuesta de Educomunicación se elabora a través de una construcción colectiva, la cual implicó: buscar coincidencias, debatir posiciones, mirar los trabajos que se realizaban en las obras de las Hijas de María Auxiliadora del Continente y hacer una lectura salesiana educomunicativa. La Propuesta de Educomunicación para la Familia Salesiana se presentó en el II Encuentro de Escuela Salesiana América. Para continuar socializando y profundizándola se realiza el Seminario Interamericano de Educomunicación en Brasil, con Ismar de Oliveira Soares, Francisco Gutiérrez, y otros investigadores versados en el tema. Y el camino de reflexión, estudio e investigación continúa; los escenarios actuales y los avances teóricos y tecnológicos producidos en este campo no dan tiempo para detener esta búsqueda ${ }^{2}$.

Em setembro de 2007, um grupo de sete universidades salesianas (da Itália, Índia, Argentina e Equador) reuniu-se em São Paulo para analisar sua contribuição à formação do especialista na relação Comunicação/Educação. O compromisso da família salesiana com o tema é confirmado e revigorado em dois congressos continentais: o primeiro, em maio, em Brasília, e o segundo, a ser realizado em outubro de 2008, em Quito, Equador, envolvendo os dois ramos da Família Salesiana: o masculino e o feminino.

\section{O COMEÇO}

A década de 1980 e os inícios dos anos 1990 revelaram alguns nomes do Departamento de Comunicações e Artes - CCA/USP, com notável capacidade de atrair estudantes ao programa de pós-graduação da ECA/USP ${ }^{3}$. Ao ingressar na Escola, por concurso público, em 1988, e com experiência acumulada no campo da educação para a comunicação ${ }^{4}$, compreendemos, imediatamente, que havia naquele espaço um potencial a ser explorado: colocar à disposição da sociedade o conhecimento acumulado pela ECA no campo da inter-relação Comunicação e Educação. Propusemos, então, e implementamos, com a colaboração de todos os colegas do Departamento, um Curso de Especialização na área, com 360 horas de atividades, distribuídas em núcleos teóricos, oficinas e monografia final; contamos, para tanto, com o apoio de outros Departamen- 
tos $^{5}$ e da Faculdade de Educação ${ }^{6}$. Foram atendidos dois grupos, formando, ao todo, 80 especialistas, alguns dos quais seguiram carreira acadêmica na própria ECA. O curso foi interrompido em 1992, para dar ao Departamento condições de apresentar, dois anos depois, no contexto da profunda reforma curricular promovida pela direção da Escola, uma proposta de se levar a formação em Comunicação e Educação para o nível da graduação, criando-se, na própria Escola, um bacharelado e uma licenciatura na área.

A recusa da ECA em considerar a hipótese levou o grupo de professores e pesquisadores interessados no tema a investir em pesquisas e na extensão cultural, com a intenção de deixar evidente ao mundo acadêmico as opções que a sociedade civil já vinha fazendo há algumas décadas. Nesse sentido, além dos cursos de extensão que atenderam, em seu conjunto, a mais de 20 mil matriculados, ganharam especial significado três iniciativas tomadas por grupos de docentes do Departamento de Comunicações e Artes, e que permanecem vigentes, com sucesso, até o presente momento: um Curso de Pós-Graduação Lato Sensu em Gestão de Processos Comunicacionais, com dois núcleos temáticos sobre o tema (um voltado para a comunicação no ensino formal e, outro, dedicado às práticas de educação para a comunicação na América Latina); um periódico especialmente dedicado ao tema (a revista Comunicação \& Educação) e, finalmente, um Núcleo de Pesquisa em Comunicação e Educação, o NCE/ USP. Cada uma destas experiências e as pessoas nelas envolvidas tiveram pesos específicos na formulação de teorias que contribuíram para a sistematização do conceito da Educomunicação. O Programa de Pós-Graduação reconheceu o fato e transformou, em 2005, a linha de pesquisa em Comunicação e Educação na atual linha Educomunicação.

\section{O CONCEITO}

O conceito da Educomunicação costumava ser empregado, nos anos 1980, pela UNESCO e por pesquisadores como Mario Kaplún, para designar genericamente determinados parâmetros didáticos voltados à educação ante os efeitos da mídia (os cursos de leitura crítica da comunicação). Foi justamente este o termo que o NCE/USP elegeu para classificar o que havia descoberto em 1998, ao concluir uma pesquisa junto a agentes culturais de 12 países da América Latina, Portugal e Espanha: a emergência de um novo campo de intervenção social?

Ressemantizado, o conceito passou a denominar não apenas um determinado ângulo programático da interação comunicação/educação (o tradicional tema da educação ante os meios), mas o conjunto dos elementos reconhecidos, na prática dos agentes culturais do continente, como constitutivos de um novo modo de se trabalhar a interface. Nessa tradição, a Educomunicação foi, então, descrita pelo NCE/USP como o

[...] conjunto das ações inerentes ao planejamento e avaliação de processos, programas e produtos de comunicação implementados com intencionalidade no então Instituto Metodista de Ensino Superior de São Bernardo do Campo, entre 1974-1980; Coordenação do Projeto LCC - Leitura Crítica da Comunicação, da UCBC - União Cristã Brasileira de Comunicação Social (1980-1986); Colaboração com as Edições Paulinas para a criação do SEPAC - Serviço à Pastoral da Comunicação, em 1982, com atividades voltadas para o campo da educação para a comunicação, incluindo a publicação de uma coleção de manuais sobre o tema.

5. Entre eles, José Coelho Sobrinho (Jornalismo). Já no início dos anos 2000, passamos também a contar com Marília Franco (Cinema, Rádio e TV) e Brasilina Passarelli (Biblioteconomia) em projetos encabeçados por docentes do CCA no campo da comunicação educativa.

6. Nomeadamente, as professoras Maria Felisminda Fusari e Heloisa Dupas Penteado, que ofereceram aulas nas duas edições do curso de especialização.

7. A pesquisa, apoiada pela FAPESP, foi realizada com um grupo de 172 especialistas de 12 países da América Latina, entre 1997 e 1999. A investigação contou com a colaboração de uma equipe que teve, entre seus membros, pesquisadores como Profa. Dra. Maria Cristina Costa, e estudantes de Iniciação Científica, como Patrícia Horta, Andrea Egler e Eliany Salvatierra. Seus resultados foram confirmados em pesquisa de Angela Shaun com 100 produtores culturais e estudiosos da Bahia tendo sido reavaliados em estudo por nós realizado entre 1999 e 2000 com agentes do campo, nos Estados Unidos. 
comunicação \& educação • Ano XIII • Número 3 • set/dez 2008

educativa, destinado a criar e fortalecer ecossistemas comunicativos abertos, criativos, sob a perspectiva da gestão compartilhada e democrática dos recursos da informação ${ }^{8}$.

A originalidade deste conjunto de ações residia especialmente no referencial teórico-metodológico que dava suporte às distintas áreas de intervenção do novo campo. Reconhecia-se, de fato, pela pesquisa, que o trabalhador do novo campo tinha opções diferentes, segundo a diversidade de atuações que caracterizavam a prática do campo emergente, entre as quais:

a) as diferentes vertentes da educação para a comunicação, que, partindo da análise da produção midiática, mobilizavam os agentes culturais no sentido de se articularem por políticas democráticas de comunicação, em nível macro;

b) a mediação educomunicativa, permitida pela presença das tecnologias nas práticas educativas e que, ao superar a visão funcional e mecanicista das tecnologias educativas, fazia da inclusão midiática e do domínio sobre as tecnologias uma forma de democratizar o acesso não só ao conhecimento, mas à própria forma de se fazer a ação política;

c) a expressão comunicativa através das artes, com a valorização do potencial criativo dos sujeitos e grupos sociais em suas práticas de intervenção social;

d) a gestão da comunicação nos espaços educativos, contemplando todos os esforços no sentido de planejar e executar políticas de comunicação, numa perspectiva democrática e participativa, a serviço das comunidades; e, finalmente,

e) a própria reflexão epistemológica sobre os fundamentos e os procedimentos adotados pelos agentes do campo, de maneira a criar instrumentos de vigilância epistemológica sobre a prática em andamento. O educomunicador passava a ser reconhecido como o sujeito com habilidade para incursionar numa ou em várias destas áreas de intervenção social, simultaneamente, desde que inspirado pelo mesmo referencial teórico-metodológico, ressalvadas as especificidades próprias de cada área, levando em conta, naturalmente, o caráter interdisciplinar e interdiscursivo do novo campo.

8. SOARES, Ismar de Oliveira. Educomunicação: um campo de mediações. Revista Comunicação \& Educação. São Paulo: CCA/Moderna, ano 7, p. 12-24, set./dez. 2000.

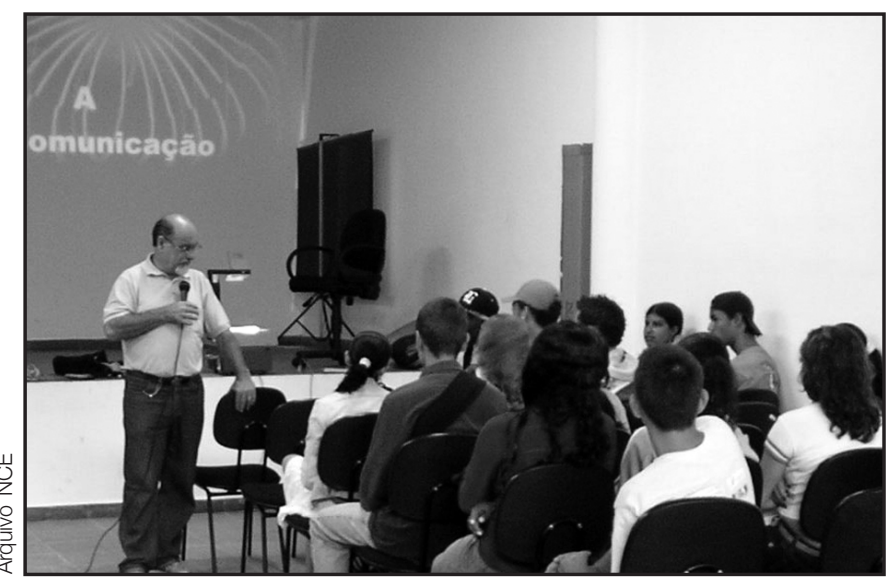

Os dados de sua pesquisa sobre o consumo crescente do universo digital na internet incentivam o professor Ismar a enfatizar que os maiores consumidores da rede são as crianças e os adolescentes, para os quais os educadores devem voltar a atenção. 
A definição entendia como espaços educativos todos os ambientes onde ocorria ou poderia ocorrer a intencionalidade de se promover a formação humana e o aprendizado numa perspectiva construtivista e participativa, mediante a prática da comunicação dialógica, incluindo tanto a educação formal (escolar, curricular), seja de forma presencial, seja a distância, quanto a não-formal (popular, não-sistemática) e a informal (midiática, esporádica).

A pesquisa constatou que a raiz da prática que consubstancia o novo campo, seu locus de origem, esteve e se mantém centrada no esforço da sociedade em buscar formas alternativas de expressão, portanto, na denominada comunicação popular, vigente há pelo menos cinqüenta anos. No caso, a Educomunicação não invade o espaço do alternativo, como temem alguns, mas reconhece sua dependência com relação a ele e o assume como sua fonte de inspiração.

Com este significado plural e abrangente, assim que anunciado na revista Contato $^{9}$, então publicada em Brasília, pelo gabinete do Senador Artur da Távola, o conceito da Educomunicação ganhou estrada, mobilizando empreendedores culturais, comunicadores, educadores e especialmente estudantes de todos os níveis (do fundamental ao superior); convertendo-se, aos poucos, em referência para políticas públicas, à medida que era adotado por programas governamentais, gerando, em conseqüência, um montante significativo de pesquisas acadêmicas, especialmente na ECA/ $\mathrm{USP}^{10}$.

\section{POLÍTICA PÚBLICA}

Foi em São Paulo, em novembro de 1999, que o Ministério da Educação acolheu publicamente e pela primeira vez o conceito, após tomar conhecimento dos resultados da pesquisa do NCE/USP, incorporando-os ao documento final do encontro Mídia e Educação, que reunira 150 empresários, produtores e autoridades do campo da comunicação social e da educação de todo o País. Recomendava o documento que as universidades flexibilizassem seus currículos, inserindo conhecimentos e práticas da área educacional para que o profissional de comunicação tivesse a possibilidade de ampliar sua atuação como educomunicador, definindo-o como "o novo profissional que atua ao mesmo tempo nos campos da Educação e da Comunicação, motivado pela oportunidade de formar cidadãos críticos, participativos e inseridos em seu meio social" ${ }^{\prime 1}$.

Entre 2001 e 2004, foi a vez de a Prefeitura de São Paulo eleger o conceito para dar sustentação a um vasto programa de combate à violência nas escolas públicas de ensino fundamental, levando a linguagem radiofônica a 455 unidades de ensino, mediante o projeto denominado "Educomunicação pelas Ondas do Rádio" (Educom.rádio), implementado pelo NCE/USP com a colaboração de quase todos os professores do Departamento de Artes - CCA/USP, além de outros 450 estudantes de universidades da Região Metropolitana de São Paulo ${ }^{12}$; e, ao final de três anos e meio de trabalho, formou aproximadamente 10 mil pessoas, entre professores, alunos e membros da comunidade escolar. Uma lei aprovada pela Câmara Municipal em 2004 (Lei Educom) garantiu a continui-
9. SOARES, Ismar de Oliveira. Comunicação e educação: a emergência de um novo campo e o perfil de seus profissionais. Contato, Brasília ano 1, n. 2, p. 19-74 jan./mar. 1999.

10. Mais de 80 trabalhos de pesquisa foram produzidos na linha de pesquisa em educomunicação, somente na ECA, desde o fim da pesquisa de 1999 até o presente momento. Parte destas pesquisas busca sistematizar a prática educomunicativa de instituições como A Escola do Futuro e do próprio NCE/USP.

11. Documento Mídia e educação. Brasília: MEC, 2000. p. 31.

12. Ao todo, o NCE/USP contou, neste projeto, com mais de 600 colaboradores, distribuídos nas diversas tarefas próprias do cronograma de trabatho, sob a coordenaçãogeral de Patrícia Horta. Dirce Gomes, do Projeto Vida, foi a responsável por levar o Educom.rádio para a esfera da Secretaria Mu nicipal de Educação, que, na época da implantação do programa, tinha como titular o Prof. Fernando de Almeida. 
13. <http://www.blogandonasondasdoradio.blogspot.com>.

14. Adilson Odair Citelli, Maria Cristina Castilho Costa, Marília Franco e Ismar de Oliveira Soares, do CCA-USP, garantiram a orientação pedagógica do projeto, que contou com a coordenação operacional de Eliany Salvatierra e com o serviço de tutoria de 40 especialistas. Silvia Galletta, da Secretaria de Educação do Estado de São Paulo, garantiu a infra-estrutura e o acompanhamento de todo o processo até a avaliação final.

15. A equipe do NCE/USP contou com a supervisão do Prof. Ismar Soares a coordenação de Silene Lourenço. Na FUNDHAS ganhou destaque a coordenação da psicopedagoga Ana Julia Campos. dade do projeto, permitindo que, em 2008, grupos de estudantes da periferia da cidade pudessem assistir e produzir coberturas jornalísticas através da webrádio para importantes eventos internacionais ocorridos na capital paulista ${ }^{13}$.

Em 2002, o NCE/USP passou a coordenar, simultaneamente ao Educom. rádio, outro grande projeto, atendendo convite da Secretaria de Educação do Estado de São Paulo, através de um projeto vinculado à Secretaria de Educação a Distância do MEC, destinado a preparar professores para usar materiais da TV Escola em sala de aula; e, na versão do NCE/USP, ganhou a perspectiva de se discutir, de forma mais global, a própria linguagem audiovisual e usá-la na prática didática a partir de uma perspectiva de ação educomunicativa. Um total de 2 mil professores de 1.024 escolas tomou parte no projeto, denominado Educom.TV e executado na modalidade de educação a distância, produzindose, ao final, mais de 900 projetos educomunicativos, envolvendo as respectivas comunidades de ensino, especialmente os alunos ${ }^{14}$.

Entre 2005 e 2006, o MEC levou a educomunicação para os estados da Região Centro-Oeste, espaço em que o NCE/USP, trabalhando com as Secretarias de Educação dos Estados do Mato Grosso, Goiás e Mato Grosso do Sul, teve condições de atender, via plataforma virtual e oficinas presenciais, mais de 2.500 membros de comunidades educativas, incluindo as quilombolas e várias aldeias indígenas como a dos Xavantes, em Sangradouro, MT. Um fato inédito ocorreu no curso Educomrádio.centro-oeste: as mulheres indígenas, que pela cultura xavante não podem se expressar publicamente na presença de homens, passaram a falar para toda a aldeia no momento em que a rádio-escola iniciou suas transmissões. Instadas a fechar a rádio pelo cacique, as meninas se rebelaram: "Foi o cacique maior que mandou a rádio para nós", justificavamse, aludindo ao vínculo do programa com a Presidência da República, numa referência explícita ao caráter de política pública que caracterizava o projeto.

A partir de 2005, a Educomunicação foi implantada na FUNDHAS - Fundação Helio Augusto de Sousa, da Prefeitura de São José dos Campos, permitindo a criação, em seu espaço público, do Centro de Referência em Educomunicação do Vale do Paraíba. Em 2008, um total de 50 professores e 150 estudantes da fundação responsabilizou-se não apenas pela implementação de 16 programas de educomunicação nas várias unidades da instituição, atendendo mais de 2 mil estudantes, como também pela difusão do conceito e de suas práticas junto a professores e alunos das redes municipais e estaduais de ensino, através de oficinas administradas pelo Centro de Referências ${ }^{15}$.

O contato e a colaboração entre o NCE/USP e Brasília, no campo da educomunicação, teve continuidade, a partir de 2005, em três ações: uma com o Ministério do Trabalho e Emprego (Projeto Geração Cidadã, em Embu das Artes, com 200 horas de trabalho junto a 2 mil adolescentes e jovens, mediante o uso da informática, com a produção de 250 blogs, e da linguagem radiofônica, para discutir a empregabilidade, destacando-se como ponto alto a acolhida dada a jovens portadores de deficiência física); uma segunda com o Ministério do Meio Ambiente (workshops e assessoria para discutir e criar o Programa 


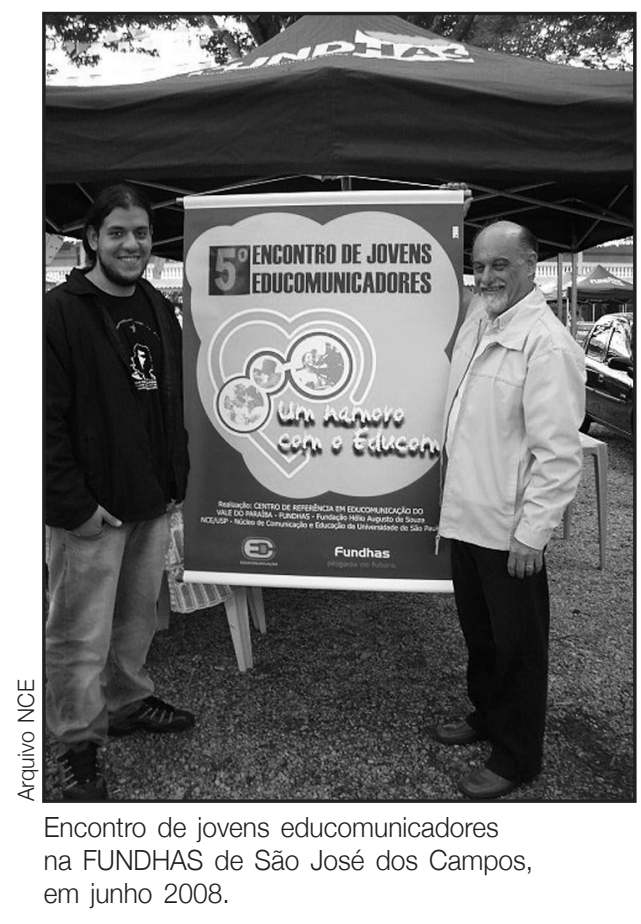

de Educomunicação Socioambiental) e, finalmente, uma terceira, com o MEC (programa de educação continuada Mídias na Educação, produzindo quatro módulos sobre o tema do rádio, incluídos na plataforma do curso, e a oferta de tutoria para mais de 3 mil cursistas originários do Estado de São Paulo).

\section{MÍDIA-EDUCAÇÃO OU EDUCOMUNICAÇÃO?}

Como já afirmamos em outros momentos, a pesquisa do NCE/USP detectou que foi na sociedade civil, no espaço das lutas políticas contra as ditaduras na América Latina e na defesa dos interesses das minorias em países como o Brasil, que a Educomunicação se forjou e ganhou densidade. No caso, não foi exata ou exclusivamente a perspectiva da melhoria da performance do professor através do uso das tecnologias (áreas da didática e da tecnologia educativa) que caracterizou o movimento, mas expressamente a luta social pelo direito à expressão, mediante a definição de políticas de ação para os agentes culturais, entre eles, numerosos professores (área da educação popular e da comunicação alternativa). Nesse sentido, foi também nas agências a serviço do movimento social, no amplo espaço denominado Movimento Social, que a educomunicação se legitimou, por meio do emprego do teatro, da música, dos boletins mimeografados, das rádios comunitárias e do vídeo popular, ao longo das décadas que constituíram a segunda metade do século XX. Somente mais tarde, já nos anos 1980, é que o procedimento chegou à esfera pública e começou a ser notado pela mídia e aplicado ao ambiente escolar.

Isso explica as conotações diferentes atribuídas, hoje, respectivamente, aos conceitos de Mídia-Educação e de Educomunicação. O primeiro traduz a preocupação da educação formal com a mídia, tanto no sentido de analisá-la quanto no de usá-la como recurso para garantir a melhoria da educação, ou mesmo no trabalho dos mestres com seus alunos. No caso, o que está em jogo é a relação entre sistema de ensino e sistema midiático, vistos sob a ótica da eficiência do ensino, replicando modelos europeus ou norte-americanos (media education, media literacy). Já o segundo conceito - o da Educomunicação -, revela a decisão política de grupos organizados da sociedade, inicialmente no âmbito da educação não-formal, de preparar o cidadão para assumir sua condição de agente comunicativo através do reconhecimento e do exercício compartilhado do direto universal à expressão. Aqui, o que está em causa é a experiência pro- 
16. Ver BARBERO, Jesús Martín. La Educación desde la Comunicación. Buenos Aires: Grupo Editorial Norma, 2002.

17. Informações sobre - Summit podem ser encontradas no site da Multirio: <http://www. multirio.rj.gov.br>.

18. ROSSETTI, Fernando. Projetos de educação, comunicação \& participação: perspectivas para políticas públicas. UNICEF, 2004. Disponível em <http://rossetti.sites. uol.com.br>.

19. Disponível em: <http://www.redecep. org.br>.

20. Do que é exemplo a programação da TV Cultura, em São Paulo, e do Canal Futura, no Rio de Janeiro; a página "Pais \& Mestres" do Jornal da Tarde, em São Paulo, entre 2006 e 2007; os trabalhos da mídia impressa como os da revista Nova Escola e Carta Capital, bem como os numerosos sites educativos na web.

21. Com projetos como "Nas Ondas do Rádio", na rede do Município de São Paulo, e "Educom", na FUNDHAS, em São José dos Campos, SP. cessual da ação comunicativa e sua intencionalidade política, à luz da reflexão latino-americana em torno das teorias das mediações ${ }^{16}$.

Na prática, o que é difícil para os adultos, preocupados em definir territórios político-conceituais, não oferece dificuldade para crianças, adolescentes e jovens: entender seu papel no processo de produção midiática dentro desta nova visão. Um dos exemplos mais vibrantes da clareza dos jovens quanto ao significado do conceito de participação educomunicativa ocorreu, recentemente, num evento protagonizado por adultos e destinado a discutir a mídia de qualidade para as novas gerações. Foi em abril de 2004, no Rio de Janeiro, durante o Summit Media for Children ${ }^{17}$. Na ocasião, 150 jovens provenientes de 45 países, reunidos em oficinas de produção de arte e de programas de comunicação, decidiram, a certo momento, nas atividades, produzir um documento em que afirmaram, sem temor de confrontar-se com os adultos: "Mídia de qualidade é aquela que nós - crianças e jovens - fazemos, ou que os adultos fazem conosco". Para a nova geração, a participação passava a ser indicador da qualidade, para além da própria estética e da própria tecnologia.

$\mathrm{Na}$ verdade, seria impossível saber a quantidade de crianças, adolescentes e jovens atendidos, hoje, no Brasil, por ONGs que trabalham com a perspectiva participativa do uso da mídia em seus projetos de educação. Seriam eles 20, 50, 100 mil? O que se conhece é que os resultados têm sido sempre excelentes, motivando até mesmo numerosas empresas envolvidas com o chamado Terceiro Setor a garantir sustentação financeira para projetos no campo. A grande pergunta, em conseqüência, vem a ser outra: o que tem sido bom para esses 20, 50 ou 100 mil jovens não poderia igualmente ser bom para os 20, 30 milhões de crianças, adolescentes e jovens que freqüentam as escolas públicas? Esta vem sendo a batalha do NCE/ECA ao longo dos últimos vinte anos: promover o mais intenso programa de extensão cultural da história da USP, para promover o direito da infância em ter acesso a políticas públicas que garantam a mídia a todos.

O esforço da ECA/USP acabou sendo notado pela UNICEF, que incluiu a prática educomunicativa do NCE no rol dos programas analisados numa pesquisa empreendida, em 2004, pelo jornalista Fernando Rossetti ${ }^{18}$. Um dos resultados práticos da pesquisa foi a criação da Rede CEP - Comunicação, Educação e Participação, que conta com a presença das organizações que foram objeto dos estudos de Rossetti, incluindo o NCE/USP ${ }^{19}$.

\section{ASSIM NA MÍDIA COMO NA ESCOLA}

Ainda que não tenham sido o berço da prática educomunicativa, a educação informal, implementada, hoje, através da mídia ${ }^{20}$, assim como a própria educação formal, de caráter escolar ${ }^{21}$, apresentam-se, hoje, como espaços vitais para o desenvolvimento do conceito.

Trata-se, em termos de princípios, do reconhecimento do direito de aproximadamente 30 milhões de crianças e adolescentes do Brasil a terem, de um 


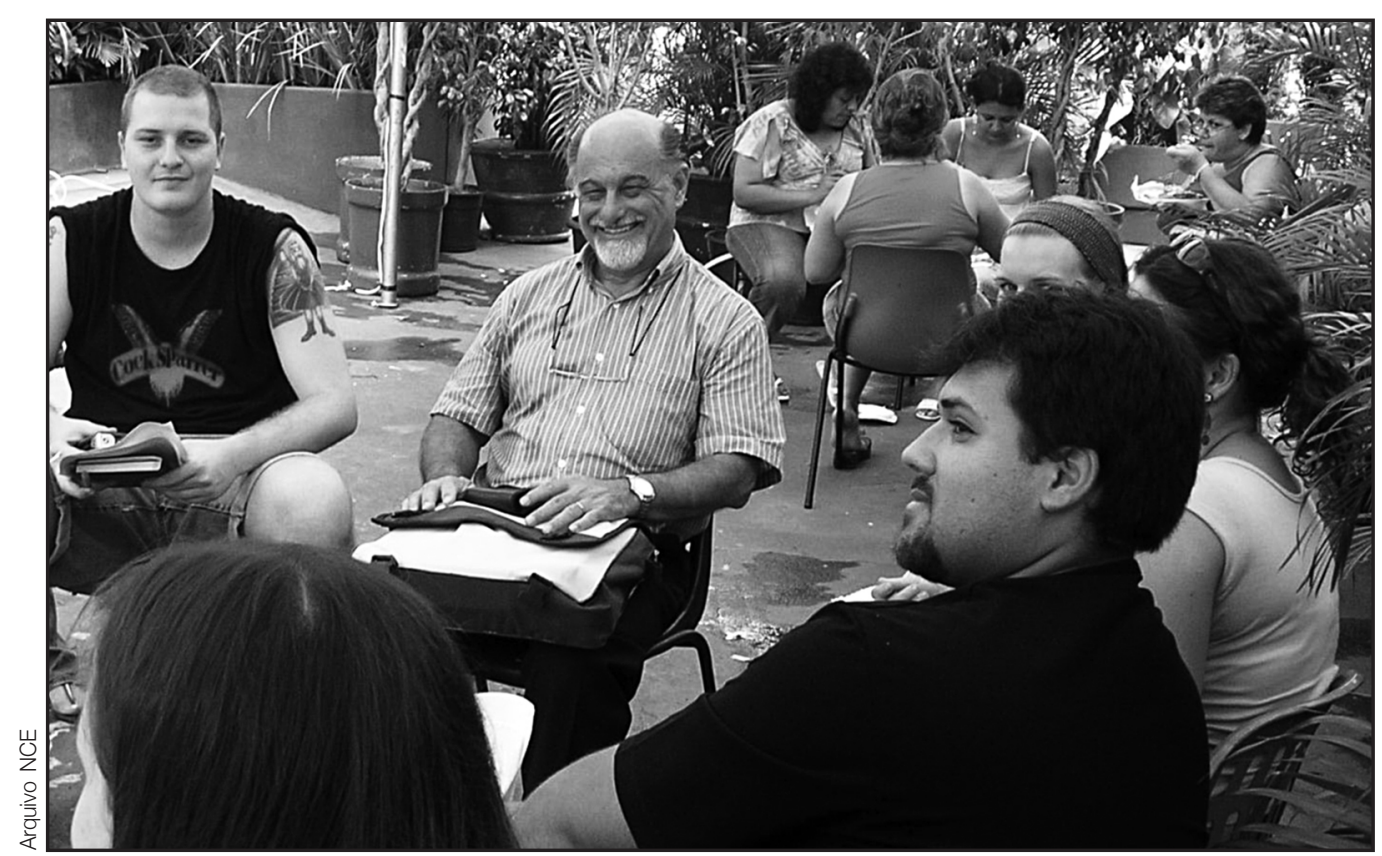

A criação de uma Licenciatura em Educomunicação na Escola de Comunicações e Artes é o próximo passo do Prof. Dr. Ismar de Oliveira Soares e do grupo de professores do Departamento de Artes.

lado, acesso a uma programação de qualidade veiculada pela mídia e, de outro, condição de serem protagonistas de seu próprio desenvolvimento humano, tecnológico e profissional, através de uma prática pedagógica que favoreça o exercício coletivo e colaborativo do fazer comunicacional, contando professores e alunos com a infra-estrutura necessária e o apoio de seus educadores, transformados, assim, em adultos significativos para seus alunos.

Para o propósito da meta a ser alcançada, nomes como mídia-educação ou, mesmo, comunicação educativa são igualmente válidos. É o que entendemos como educomunicação possível, levando em conta que vivemos em uma sociedade complexa e pluralista, em que os modelos de gestão se justapõem. O importante é garantir a coerência do processo aceito na negociação entre a autoridade estabelecida e o promotor do projeto ou do programa em foco.

\section{ESCOLA DE TEMPO INTEGRAL, A ESPERANÇA!}

Os obstáculos, contudo, são numerosos e solidamente estabelecidos, especialmente pelos paradigmas da educação tradicional que enxergam a comunicação como um mero conjunto de instrumentos a serviço dos processos didáticos. Mas, apesar de toda sorte de resistências, às iniciativas já apresentadas somase uma brecha no campo da educação formal, quando o sistema de ensino passa a discutir a necessidade de implementar a escola integral, de oito horas, superando a visão conteudística e muitas vezes fragmentada da educação curricular. No caso, a educomunicação se apresenta como uma alternativa, uma forma diferenciada de se trabalhar o contraturno. 


$$
\text { comunicação \& educação • Ano XIII • Número } 3 \text { • set/dez } 2008
$$

Referencial teórico, para tanto, existe, assim como a possibilidade de se contar, mesmo em escolas pobres, com uma infra-estrutura laboratorial mínima. Faltam, sem dúvida, conhecimento técnico sobre o tema e, especialmente, gestores preparados. Para que programas desta ordem se tornem viáveis, a ECA/USP propõe a criação de sua Licenciatura em Educomunicação, mantendo-se disposta a continuar seu diálogo com a sociedade (com os profissionais da mídia e com as autoridades do sistema educativo) sobre o assunto.

\section{O EDUCADOR DO ANO É UM EDUCOMUNICADOR!}

O sugestivo título da matéria do site da Rede CEP (www.redecep.org.br), por ocasião da entrega do prêmio conferido, em 2007, pelo Grupo Educartis, depois de ouvir internautas de todo o País, aponta para um fato significativo: o educomunicador é essencialmente um educador. No caso, centenas de profissionais que decidiram optar pela convergência propiciada pela inter-relação comunicação/educação sentiram-se, todos e cada um, premiados. Os sinais que apontam para o acerto em se praticar a educomunicação são tão grandes e tão sólidos que, a cada dia, novos educadores do ano despontam, a cada manhã de trabalho, em cada canto do País. A eles se associam jovens apaixonados, como os garotos e garotas da FUNDHAS - Fundação Hélio Augusto de Souza, de São José dos Campos-SP, enamorados pela educomunicação.

\section{REFERÊNCIAS BIBLIOGRÁFICAS}

BACCEGA, Maria Aparecida. Tecnologia, escola, professor. Revista Comunicação \& Educação, São Paulo: CCA/Moderna, v. 3, n. 7, set./dez. 1996.

BRAGA, José Luiz; CALAZANS, Regina. Comunicação \& Educação: questões delicadas na interface. São Paulo: Hacker Editores, 2001.

CALVANI, Antonio. Educazione, comunicazione e nuovi media. Torino: UTET Librería, 2008.

CITELLI, Adilson Odair. Palavras, meios de comunicação e educação. São Paulo: Cortez, 2006.

KAPLUN, Mario. Processos educativos e canais de comunicação. Revista Comunicação e Educação, São Paulo: CCA/Moderna. n. 1, jan./abr. 1999.

MARTÍN-BARBERO, Jesús. La educación desde la comunicación. Buenos Aires: Grupo Editorial Norma, 2002.

MINISTÉRIO DA EDUCAÇÃO. Mídia \& educação, perspectivas para a qualidade da informação. Brasília: MEC, 2000.

SCHAUN, Angela. Comunicação e educação: a transversalidade de ritmos e falas. Tese doutoral, UFRJ, 1999. 
SCHAUN, Angela. La comunicación/educación como nuevo campo del conocimiento y el perfil de su profesional. In: VALDERRAMA, Carlos Eduardo. Comunicación-Educación, coordinadas, abordajes y travesías. Bogotá: Siglo dei Hombre, 2000.

Contra a violência: experiências sensoriais envolvendo luz e visão (Educação para a mídia e tecnologia educacional de um ponto de vista latinoamericano). In: VON FEIILITZEN, C.; CARLSSON, U. (Orgs.). A criança e a mídia: imagem, educação, participação. São Paulo: Cortez e Unesco, 2002. v. 1.

. A busca da natureza dialógica da educomunicação. In: GOTTLIEB, Liana

(Org.). Comunicação e mercado. 1. ed. São Paulo: Iglu Editora, 2004. v. 1.

. A ECA/USP e a Educomunicação: a consolidação de um conceito, em dezoito anos de trabalho. Comunicação \& Educação, São Paulo: CCA-ECA-USP/ Paulinas, v. 2, maio/ago. 2007.

- A Educomunicação como Processo de Gestão Comunicativa. In:

FÍGARO, Roseli (Org.). Gestão da Comunicação: no mundo do trabalho, educação, Terceiro Setor e cooperativismo. São Paulo: Atlas, 2005. v. 1.

EAD como prática educomunicativa. Revista USP, n. 55, nov. 2002.

Educação para os meios nos Estados Unidos. Revista Fronteiras: Estudos Mediáticos, São Leopoldo-RS: Unisinos, v. 1, n. 1, dez. 2000.

Educommunication: an emerging new field (Educomunicação: um novo campo emergente). Telemedium, Madison, v. 46, n. 1, Spring, 2000.

Educommunication: concept and aim (Educomunicação: conceito e meta). Ucip Media Challenges Amidst Cultural And Religious Pluralism, Genebra, v. $1,2005$.

El derecho a la pantalla: de la educación a los medios a la educomunicación en Brasil (O direito a uma tela: da educação para os meios à Educomunicação no Brasil). Comunicar, Huelva: Espanha, 30, XV, 2008.

. NCE - A Trajetória de um Núcleo de Pesquisa da USP. Comunicação \& Educação, São Paulo: CCA-ECA-Paulinas, v. X, n. 1, jan./abr. 2005.

Rádio na escola: a palavra viva. Carta Capital, São Paulo, n. 9, 2006.

TV de qualidade, a revolução virá com as crianças e os jovens. Presente: Revista de Educação, Salvador, v. 1, 2005.

Voluntários, Terceiro Setor e Gestão da Comunicação. In: COSTA, Maria Cristina Castilho (Org.). Gestão da Comunicação. 1. ed. São Paulo: Atlas, 2006. v. 1.

. Sociedade da informação ou da comunicação? São Paulo: Cidade Nova, 1996. 
comunicação \& educação • Ano XIII • Número 3 • set/dez 2008

SCHAUN, Angela. Comunicação e educação: a emergência de um novo campo e o perfil de seus profissionais. Contato, Brasília, ano 1, n. 2, jan./mar. 1999.

\section{Endereço eletrônico}

ROSSETTI, Fernando. Mídia e escola: perspectivas para políticas públicas. UNICEF/Educarede. Edição Jogo de amarelinha, 2005. Disponível em: <http:/ / rossetti.sites.uol.com.br>. 